\title{
Anaesthesia for thoracoscopic pulmonary lobectomy
}

This report describes the anaesthetic management of a new surgical procedure - pulmonary lobectomy accomplished by minimal invasive surgery (MIS) techniques. Upper and middle pulmonary lobectomy were performed uneventfully during general anaesthesia in a 76-yr-old woman. No similar report has yet appeared in the literature. Important anaesthetic considerations include safety concerns, the need for differential lung ventilation, and the problems inherent in a lengthy operation. In the appropriate clinical setting, anaesthesia and surgery for major pulmonary resections accomplished by MIS techniques can be performed safely and effectively.

Cette observation décrit la prise en charge anesthésique de la lobectomie pulmonaire réalisée par thoracoscopie. Une lobectomie des lobes supérieur et moyen est réalisée sous anesthésie générale sans complications chez une femme de 76 ans. La littérature médicale ne mentionne pas de cas identiques. Les considérations anesthésiques importantes comprennent la sécurité, le besoin de ventilation pulmonaire sélective et les problèmes propres aux interventions de longue durée. Sous des conditions clinique appropriées, on peut conduire l'anesthésie et la chirurgie pour des résections pulmonaires étendues en toute sécurité.

Many operations, formerly performed by traditional open surgical methods, can be accomplished using MIS techniques. Potential advantages include decreased postoperative pain, less interference with pulmonary function, earlier ambulation and earlier hospital discharge. Major

\section{Key words}

ANAESTHESIA: thoracic;

SURGICAL TECHNIQUES: thoracoscopic, pulmonary lobectomy.

From the Department of Anaesthesiology, Saskatoon City Hospital, Saskatoon, Saskatchewan.

Address correspondence to: Dr. Jonathan D. Lamb, Clinical Associate Professor of Anaesthesia, Department of Anaesthesiology, Saskatoon City Hospital, Saskatoon, Saskatchewan S7K 0M7. pulmonary resections are now being done in this manner. The following report describes such a case.

\section{Case report}

This 76-yr-old, otherwise healthy, $76 \mathrm{~kg}$ woman was found on a routine chest radiograph, to have a three centimetre lesion in the right infrahilar region. A CT scan showed an ill-defined spiculated lesion in the right middle lobe. Pulmonary function tests were normal. Bronchoscopy yielded negative results. A CT-guided biopsy was considered to be dangerous. Surgical resection was scheduled.

Anaesthesia was induced with lidocaine $70 \mathrm{mg}$, fentanyl $200 \mathrm{mg}$ and thiopentone $300 \mathrm{mg}$ and after succinylcholine, $70 \mathrm{mg}$, a left-sided 35 Fr. double-lumen tracheal tube was inserted. Differential lung ventilation was demonstrated clinically, and confirmed following left lateral positioning. Monitoring included intraarterial blood pressure, pulse oximetry and capnography. A trocar was introduced into the right lateral hemithorax, allowing the insertion of a thoracoscope attached to a video camera. The tracheal lumen of the tube was clamped proximally and decompressed distally, following which videothoracoscopic visualization of the right pleural cavity demonstrated rapid and complete lung decompression. Following insertion of multiple trocars, the upper and middle lobes were dissected and their hilar attachments divided and secured. The detached lobes were secured in a small plastic bag which was then extracted from the chest cavity through an enlarged (four to five centimetre) trocar site. Bronchial integrity at the surgical site was confirmed by the absence of gas bubbles in a salineflooded surgical field during sustained positive pressure following unclamping of the tracheal lumen.

Total operating room time was seven hours and forty minutes. Blood loss was approximately $500 \mathrm{ml}$. One-lung ventilation, during which $\mathrm{FIO}_{2}$ was maintained at about 0.67 , was tolerated well for the duration of the procedure. The lungs were ventilated overnight because of the patient's age, the lengthy procedure and the lateness of the day, and the trachea was extubated $14 \mathrm{hr}$ after surgery. Patient-controlled analgesia with morphine $i v$ was started on arrival in the Intensive Care Unit and continued for $60 \mathrm{hr}$, and produced satisfactory pain control. An ade- 
nocarcinoma in the resected lung tissue was identified. The patient made an uneventful recovery.

\section{Discussion}

Anaesthesia for minimal invasive surgery is rapidly forming a substantial portion of anaesthetic practice. As well as numerous intraabdominal procedures now being performed laparoscopically, several thoracic procedures, traditionally accomplished by open thoracotomy, are now successfully being done thoracoscopically. ${ }^{1}$ The thoracoscope is not new to thoracic surgeons. ${ }^{2}$ It has been used extensively for diagnostic and tumour staging procedures. The recent availability of more refined stapling and dissecting instruments, and the excellent optical capability of current video equipment, has increased the potential scope and utility of MIS techniques in thoracic surgery so that major pulmonary resections have become technically feasible. Our institution has been performing pulmonary lobectomies through the thoracoscope under video control since late 1992. Personal participation in several of these procedures suggests some pertinent anaesthetic considerations.

Firstly, the potential problems related to any thoracic surgical procedure will be present. Many patients will have malignancies subsequent to decades of heavy smoking. They deserve preoperative optimization of pulmonary function to the same extent as a patient scheduled for an open thoracotomy. Indeed, a small proportion (in our institution, $<10 \%$ ) may require conversion of the attempted thoracoscopically performed procedure to an open operation for technical or other reasons.

There is no consensus among thoracic surgeons regarding the safety of major pulmonary resection accomplished by MIS techniques. ${ }^{3}$ Loss of control of major hilar vascular structures could result in massive haemorrhage and rapid death. Current thoracoscopic instruments and techniques may be unable to deal effectively with this situation. Obviously, the anaesthetist embarking on these procedures must be prepared to deal with an acutely exsanguinating patient. This implies good vascular access and readily available blood products.

Secondly, as this case report demonstrates, thoracoscopic pulmonary lobectomy may be a very lengthy procedure. Operating times, presently ranging from six to ten hours, may decrease as surgeons gain experience. The usual concerns related to prolonged surgery apply, including temperature maintenance, hydration and positioning. The last is particularly important. Proper axillary support deserves meticulous attention in a lengthy case performed in the lateral position to minimize the possibility of bracheal plexus injury. ${ }^{4}$ In addition, prolonged surgery in this position may be associated with considerable fluid transudation in the dependent lung ${ }^{5}$ and this could exacerbate the tendency towards hypoxaemia during differential lung ventilation intraoperatively. Typically resolution occurs rapidly after surgery.

Thirdly, thoracoscopic thoracic surgery will usually require the lung to be collapsed on the operated side. This is particularly important for pulmonary lobectomy because of the unimpeded surgical visualization that is required. A double-lumen endobronchial tube will require accurate positioning, perhaps with the help of a fibreoptic bronchoscope. A paediatric bronchoscope is necessary for a $35 \mathrm{Fr}$. double-lumen tracheal tube. Inability to initiate and maintain differential lung ventilation will prevent the lobectomy from being performed through the thoracoscope and open thoracotomy will be necessary, during which complete operative lung collapse, though appreciated, is not mandatory. ${ }^{6}$ An additional reason for complete lung collapse is to allow the pulmonary lobe, once free of the adjacent lung, to be extracted through as small an intercostal incision as possible. This preserves the nature and advantage of a minimal access procedure, i.e., a very small incision, with as little muscle fibre disruption as possible.

Fourthly, postoperative pain management deserves mention. One considerable advantage to the patient of thoracoscopic surgery derives from the absence of a long intercostal incision and the avoidance of intraoperative rib-spreading required for surgical exposure during open thoracotomy. Extraction of a fully collapsed pulmonary lobe requires only a four to six centimetre intercostal incision. Though unsubstantiated, these patients appear to have considerably decreased analgesic requirements. Patient-controlled analgesia with morphine, $i v$ has proven satisfactory. An alternative would be neuraxial analgesia administered through an epidural catheter. This approach may be advantageous in those cases in which a thoracoscopic procedure progressed to an open thoracotomy.

High abdominal laparotomy and open thoracotomy are associated with considerable alteration of postoperative pulmonary function ${ }^{7}$ but this may be better preserved postoperatively following MIS techniques than after open thoracotomy. There is little objective information to support this although recent experience with laparoscopic cholecystectomy suggests that postoperative lung volumes and flow rates are less depressed than after open cholecystectomy. ${ }^{8}$ This area deserves investigation.

In summary, we describe a major pulmonary resection performed by MIS techniques. These procedures will become more commonplace and can be performed safely in the appropriate setting. Potential advantages, although unsubstantiated, include decreased postoperative pain, better preserved pulmonary function, earlier ambulation, and perhaps earlier discharge from hospital. 


\section{References}

1 Page RD, Jeffery RR, Donnelly RJ. Thoracoscopy: a review of 121 consecutive surgical procedures. Ann Thorac Surg, 1989; 48: 66-8.

2 Jacobeus HC. The practical importance of thoracoscopy in surgery of the chest. Surg Gynecol Obstet, 1921; 32: 493-6.

3 Chappel EW, McFadden D, Thomson D, Laulor BJ (Letter). Saskatchewan Medical Association Journal, 1993; 1: 22-3.

4 Kaplan JA. Complications of thoracic surgery. In: Kaplan JA (Ed.). Thoracic Anesthesia. New York: Churchill Livingstone Inc., 1983; 629.

5 Ray JF III, Yost L, Moallem $S$, et al. Immobility, hypoxemia, and pulmonary arteriovenous shunting. Arch Surg, 1974; 109: 537-41.

6 Benumof JL, Alfery DD. Anesthesia for thoracic surgery. In: Miller RD (Ed.). Anesthesia, 2nd ed., New York: Churchill Livingstone Inc., 1986; 1395.

7 Craig $D B$. Postoperative recovery of pulmonary function. Anesth Analg 1981; 60: 46-52.

8 Frazee $R C$, Roberts $J W$, Okeson GC, et al. Open versus laparoscopic cholecystectomy. A comparison of postoperative pulmonary function. Ann Surg, 1991; 213: 651-3. 